\title{
Use of Secondary Ions Mass Spectrometry (SIMS) for Cladding Materials Post- Irradiation Examination (PIE)
}

\author{
Portier S., Mine N. and M. Martin \\ Paul Scherrer Institute, Hot Laboratory Division, Villigen, Switzerland
}

Zirconium-based alloys are widely used in the field of nuclear industry as cladding for nuclear fuel in power plants. In a pressurized water reactor (PWR), boric acid is added in the coolant for reactivity control. Lithium hydroxide is added to render the coolant slightly alkaline, which helps to inhibit corrosion product deposition on the fuel cladding and reduces the corrosion rate of structural materials. On the other hand, out-of-pile experiments demonstrated that lithium increases Zircaloy corrosion rates above a certain concentration level [1]. Moreover, the corrosion phenomenon is accompanied by the release of hydrogen gas according to the redox reaction, $\mathrm{Zr}+2 \mathrm{H}_{2} \mathrm{O} \rightarrow \mathrm{ZrO}_{2}+2 \mathrm{H}_{2}$. The released hydrogen gas partly diffuses into the alloy and forms zirconium hydrides. According to the local temperature, hydrides precipitates are formed when the solubility limit of hydrogen in Zircaloy is exceeded. Their formation leads to cladding blistering and cracking: the hydrogen embrittlement. Both corrosion and H-uptake are key phenomena which reduce the cladding life time under irradiation. Postirradiation examination of irradiated cladding tubes is consequently of great interest for the understanding of the corrosion behavior. Local information (micrometer range) is required like lithium and boron concentration level (ppm range) in the oxide layer or hydrides distribution through the cladding ring. Both are data that Electron Probe Micro Analysis (EPMA) cannot provide, as these elements are too light.

A possible alternative to EPMA for the investigation of such elements is Secondary Ion Mass Spectrometry (SIMS). The ATOMIKA 4000 shielded SIMS [2] is used at the Paul Scherrer Institute for the analysis of irradiated materials since 1995.

SIMS investigations are routinely performed to assess to local distribution of the elements of interest [3], i.e. lithium and boron concentration in the outer oxide layer of the cladding. Ion images, comparable to EPMA X-Ray images, can also be obtained (Fig.1). The quantification is performed using adequate implanted standard specimens (Fig.2). The investigation of hydrides is more challenging and a new method has been recently developed after an improvement of the instrument capabilities (up-grade), allowing to perform hydrogen ion mapping with $25 \mathrm{keV}{ }^{69} \mathrm{Ga}+$ primary ions after $10 \mathrm{keV}{ }^{133} \mathrm{Cs}^{+}$ions bombardment (Fig.3) . The first results on non-irradiated hydrogenated samples have been presented last year [4].

[1] A. T. Motta and L. Q. Chen, J.O.M. (Journal of the Minerals, Metals \& Materials Society), vol. 64 (2012), p. 1403.

[2] G. Bart, O. Gebhardt, E.T. Aerne and M. Martin, IAEA TECDOC-822 (1995), p. 337.

[3] D. Lutz, Y.-P. Lin, R. Dunavant, R. Schneider, H. Yeager, A. Kucuk, B. Cheng and J. Lemons, ASTM 17th International Symposium on Zirconium in the Nuclear Industry (2013).

[4] N. Mine, S. Portier and M. Martin, accepted in Surf. Interface. Anal. (2013).

[5] The authors acknowledge funding from the PSI-FELLOW program, Grant agreement no.: 290605, and GNF and EPRI for the fruitful collaboration on irradiate cladding SIMS analyses. 


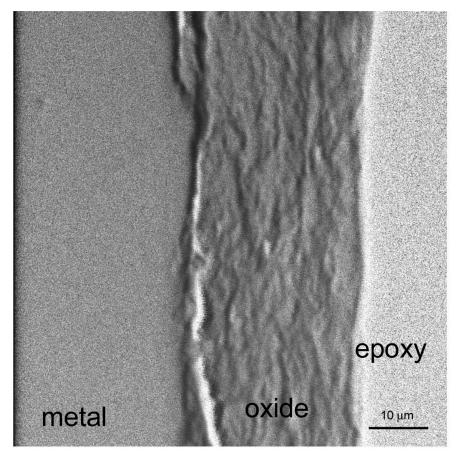

SE image

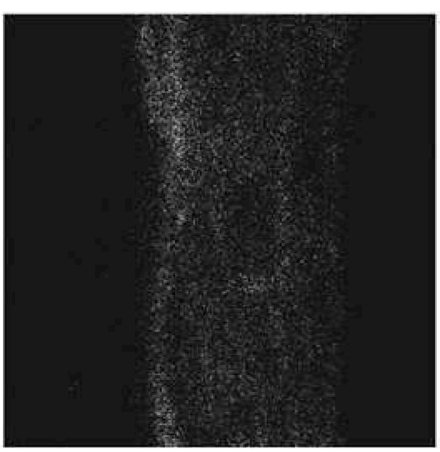

${ }^{7} \mathrm{Li}^{+}$image
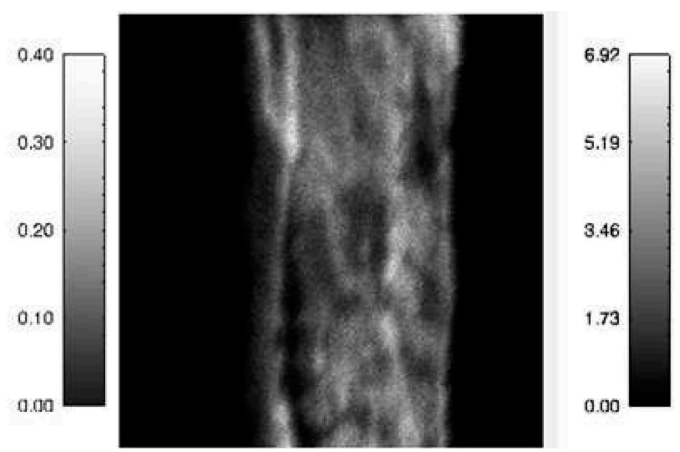

${ }^{106} \mathrm{ZrO}^{+}$image

Figure 1. : Secondary electron image compared with SIMS maps of ${ }^{7} \mathrm{Li}+$ and ${ }^{106} \mathrm{ZrO}^{+}$from $\mathrm{M} 5^{\mathrm{TM}}$ irradiated sample oxide layer [3].
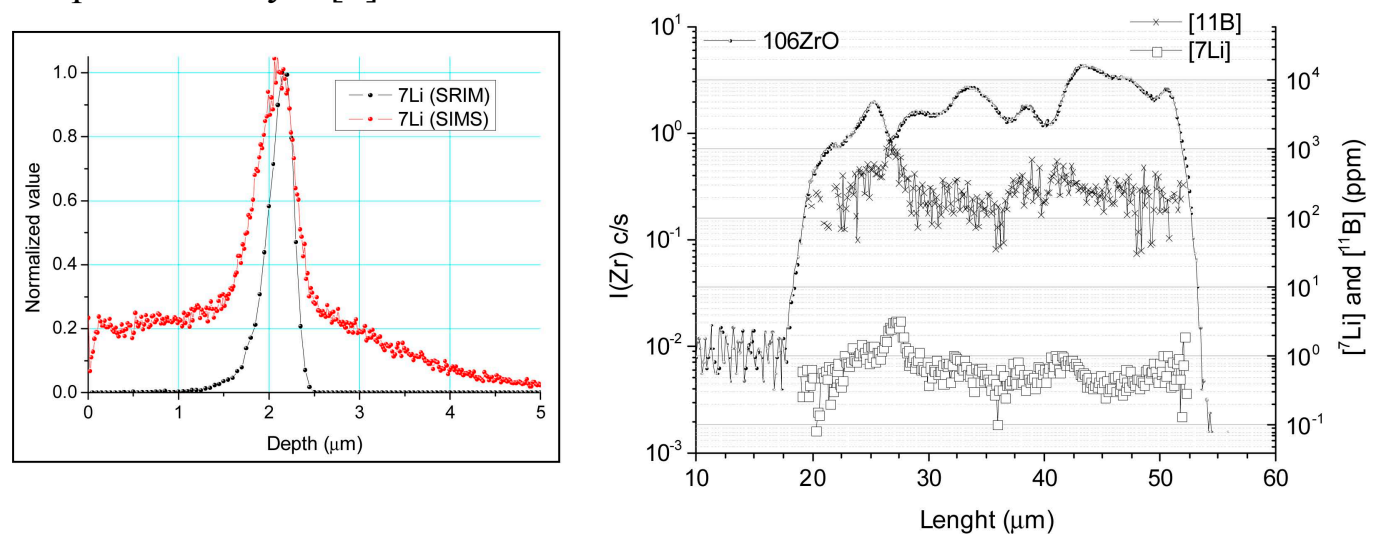

Figure 2. : From left to right: lithium profile in implanted standard specimen compared with theoretical implantation calculation (SRIM) and ${ }^{7} \mathrm{Li}$ and ${ }^{11} \mathrm{~B}$ concentration profiles across the oxide layer in M5TM irradiated sample [3].
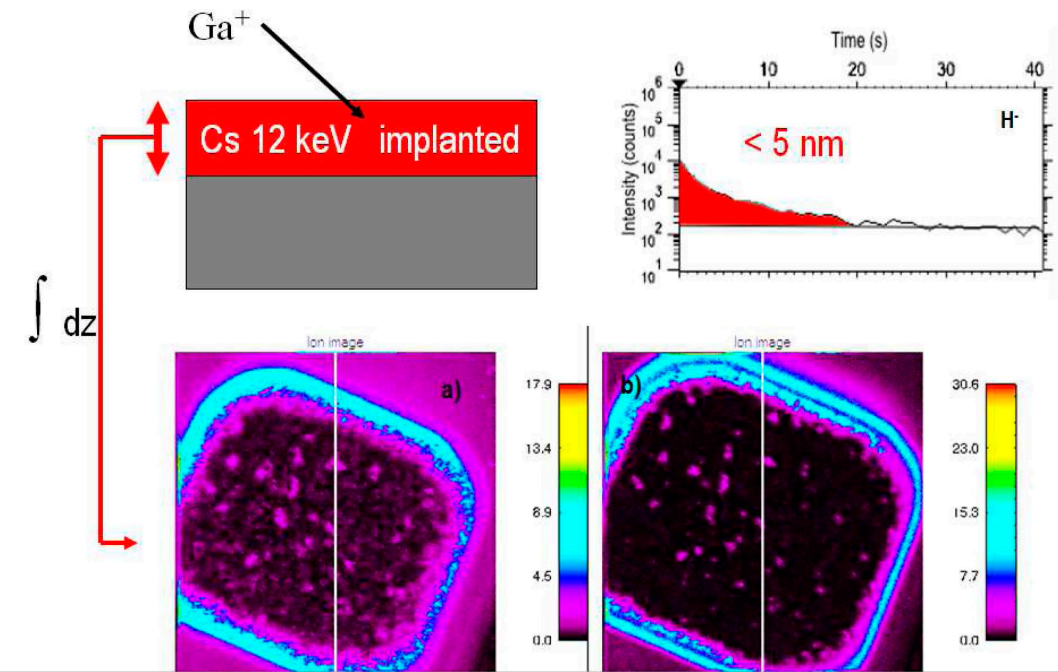

Figure 3. : Hydrogen SIMS images performed with $25 \mathrm{keV}^{69} \mathrm{Ga}^{+}$primary ions after $10 \mathrm{keV}^{133} \mathrm{Cs}^{+}$ions bombardment. Hydrides features can be observed in the Cs crater. 